\title{
Serological and Biochemical Characterization of Two Birnaviruses; VDV and YAV Isolated from Cultured Yellowtail
}

\author{
Kazuhiro Nakajima and Minoru Sorimachi \\ National Research Institute of Aquaculture, Nansei, Mie 516-01, Japan
}

(Received February 15, 1994)

\begin{abstract}
The birnaviruses, viral deformity virus (VDV) and yellowtail ascites virus (YAV) isolated from cultured yellowtail, Seriola quinqueradiata, were examined for their serological and biochemical properties. Cross-neutralization studies showed that VDV was closely related to YAV but clearly distinct from the 3 type strains of infectious pancreatic necrosis virus (IPNV). VDV and YAV contained two genome segments and mobility of the smaller segment showed a slight difference between the two. On the other hand, polypeptide electropherotypes showed a clear difference between VDV and YAV.
\end{abstract}

Viral ascites of yellowtail (Seriola quinqueradiata) fingerlings have resulted in large economic losses to yellowtail culture. A birnavirus designated as yellowtail ascites virus (YAV) was identified as a causative agent of the disease (Sorimachi and Hara, 1985) and serologically distinct from IPNV (Kusuda et al., 1993). Recently, a new epizootic occurred among yellowtail fingerlings in seawater cage. The diseased fish showed deformity of the body; scoliosis and a causative agent, tentatively designated as viral deformity virus (VDV) which was classified in the family Birnaviridae from morphological and physicochemical properties was isolated from the diseased fingerlings (Nakajima et al., 1993).

This report describes the serological and biochemical characteristics of VDV and YAV together with the serological comparison of these viruses with reference strains of infectious pancreatic necrosis virus (IPNV).

\section{Materials and Methods}

\section{Cell lines}

The CHSE-214 cell line was used in this study. The cell line was cultured at $20^{\circ} \mathrm{C}$ in minimal essential medium (MEM) supplemented with $10 \%(\mathrm{v} / \mathrm{v})$ fetal bovine serum (FBS), $50 \mu \mathrm{g} / \mathrm{ml}$ streptomycin and $50 \mathrm{IU} / \mathrm{ml}$ penicillin.

\section{Viruses}

A strain BN-1 of VDV was isolated from diseased yellowtail fingerlings which showed deformity of the body in a net cage culture in Nagasaki Prefecture, Japan (Nakajima et al., 1993). A strain YAV-1 of YAV was isolated from diseased cultured yellowtail fingerlings sampled in Kagawa Prefecture (Sorimachi and Hara, 1985). Three strains of IPNV (VR-299, Sp and Ab) of the family Birnaviridae were used as references for serological comparisons.

\section{Preparation of antisera against 5 birnaviruses}

Antisera against the five birnaviruses were obtained by injecting young rabbits with each virus preparation. The rabbits were inoculated subcutaneously with virus suspension in PBS containing 50 percent Freund's complete adjuvant. Booster injections were given twice intramuscularly biweedly, and blood was taken 1 week after the last injection. The antisera were heated to decomplementize at $56^{\circ} \mathrm{C}$ for $30 \mathrm{~min}$ before use.

\section{Neutralization tests}

Serological relatedness of VDV to YAV, VR-299, $\mathrm{Sp}$, and $\mathrm{Ab}$ was examined by cross-neutralization test using hyper-immune rabbit sera prepared against each of the 5 viruses. Neutralization tests were performed as described by Okamoto et al. (1983). Two fold dilutions of the antisera from 1/25 to $1 / 25,000$ were made in MEM without FBS, and then the dilutions were mixed with an equal volume of virus suspension of $100-700 \mathrm{TCID}_{50} / \mathrm{ml}$ on microtiter plates. The mixtures were incubated for $60 \mathrm{~min}$ at $20^{\circ} \mathrm{C}$. CHSE- 214 cells in $0.1 \mathrm{ml}$ of the culture medium were inoculated into each well of a micro- 
titer plate. The plates were sealed and incubated at $20^{\circ} \mathrm{C}$ and observed daily for 10 days. Neutralizing antibody titers were calculated according to Reed and Müench (1938) and are expressed as reciprocal of the dilution of antiserum protecting $50 \%$ of the inoculated wells. Cross-neutralization ratios $(1 / r)$ were calculated according to Archetti and Horsfall (1950) from the formula $r=\sqrt{r_{1} \times r_{2}}$ (where $r_{1}$ and $r_{2}$ are the heterologous titers divided by the homologous titers for the corresponding antisera). A value of 1.0 indicates that both viruses are serologically identical and increasing value indicate greater antigenic unrelatedness.

\section{Radiolabelling of cells}

Monolayers of CHSE-214 cell line prepared in 24 well plates were washed with MEM and preincubated for $1 \mathrm{~h}$ in methionine free MEM. The medium was then removed and the cells were inoculated with virus suspended in MEM. After a 30 min adsorption period, infected cells in 24 well plates were labelled with $0.5 \mathrm{ml}$ of MEM containing $1 / 10$ the normal concentration of methionine, 2\% FBS, and $30 \mu \mathrm{Ci}\left[{ }^{35} \mathrm{~S}\right]$ methionine (Amersham). The inoculated cells were then incubated at $20^{\circ} \mathrm{C}$ for 4 days or until CPE was complete. Mock infected cells were labelled in the same manner.

\section{Immunoprecipitation and gel electrophoresis}

Supernatants from virus infected or mock infected cells were collected and centrifuged at $12,000 \mathrm{rpm}$ for $30 \mathrm{~min}$ using a microcentrifuge and the resulting supernatant fluids were precipitated with hyperimmune rabbit serum (anti YAV). The antigenantibody complexes were allowed to form at $4^{\circ} \mathrm{C}$ overnight. The immune complexes were treated with Protein A-Sepharose CL-4B beads (Pharmacia Fine Chemicals), and after constant shaking at room temperature for $15 \mathrm{~min}$, the beads were collected by centrifugation of $10,000 \mathrm{rpm}, 1 \mathrm{~min}$ and washed twice with lysis buffer and once with $0.01 \mathrm{M}-\mathrm{Tris}-\mathrm{HCl}$ pH 8.0. Then, the immunoprecipitates were dissolved in sample buffer (Laemmli, 1970) and subjected to SDS-PAGE (separation gel 10\% polyacrylamide gel; spacer gel, 4\%) as described by Nakajima et al. (1986). The polypeptide bands were stained with Coomassie Brilliant Blue. For preparation of fluorograms, the gels were treated with $1 \mathrm{M}$ sodium salicylate by the method of Chamberlain (1979), dried and applied to X-ray film.

\section{Virion RNA analysis}

Analysis of the virion RNA was done as described by Hedrick et al. (1985). VDV and YAV had been propagated in CHSE-214 cells grown in $25 \mathrm{~cm}^{2}$ flasks. After extensive CPE had appeared, the culture fluid was harvested and centrifuged. The supernatant was mixed with N-lauroylsarcosine to a final concentration of $0.1 \%(\mathrm{w} / \mathrm{v})$. The virions were sedimented by centrifugation, the pellet was incubated with $0.5 \%$ SDS and $200 \mu \mathrm{g} / \mathrm{ml}$ proteinase $\mathrm{K}$ in TNE buffer $(0.01 \mathrm{M}$ Tris, $0.1 \mathrm{M} \mathrm{NaCl}, 0.001 \mathrm{M}$ EDTA, pH 7.5). An equal volume of $2 \times$ SDS sample buffer was added and boiled for $1 \mathrm{~min}$. After electrophoresis for $22 \mathrm{~h}$ at $9 \mathrm{~mA}$, the separated RNA segments were stained with silver as described by Merril et al. (1981).

\section{Results}

\section{Neutralization tests}

Neutralization titers of the antisera against homologous and heterologous viruses were shown in Table 1. Cross-neutralization ratios of $1 / r$ for all strains were shown in Table 2. The value of $1 / r$ between VDV and YAV was 1.04, indicating a close antigenic relationship between these two viruses. The value showed that YAV and VDV were the least related to strain VR-299 of IPNV (a large $1 / r$ value) and that they were distantly related to strain $\mathrm{Sp}$ and $\mathrm{Ab}$ of IPNV.

\section{Polyacrylamide gel elctrophoresis of viral RNA}

The 5 birnaviruses showed contained two RNA segments (Fig. 1). The mobility of larger segment of VDV was the same as those of YAV but the mobility of smaller segment of VDV was slightly different from that of YAV.

Table 1. Titers of antisera of five fish birnaviruses determined by cross-neutralization test

\begin{tabular}{lrrrrr}
\hline \hline \multirow{5}{*}{ Birnavirus } & \multicolumn{5}{c}{ Antisera against } \\
\cline { 2 - 6 } & VDV & YAV & \multicolumn{1}{c}{ Sp } & \multicolumn{1}{c}{ Ab } & VR-299 \\
\hline VDV & 4,850 & 3,200 & 1,600 & 447 & 310 \\
YAV & 6,400 & 4,525 & 2,263 & 447 & 200 \\
Sp & 141 & 41 & 2,011 & 400 & 1,013 \\
Ab & 1,393 & 87 & 126 & 5,198 & 800 \\
VR-299 & 492 & 492 & 289 & 141 & 15,759 \\
\hline
\end{tabular}


Table 2. Antigenic relationships among five fish birnaviruses

\begin{tabular}{lccrrr}
\hline \hline \multirow{2}{*}{ Birnavirus } & \multicolumn{6}{c}{ Antisera against } \\
\cline { 2 - 6 } & VDV & YAV & \multicolumn{1}{c}{ Sp } & \multicolumn{1}{c}{ Ab } & VR-299 \\
\hline VDV & 1.00 & 1.04 & 6.58 & 6.37 & 22.45 \\
YAV & - & 1.00 & 10.00 & 24.38 & 27.08 \\
Sp & - & - & 1.00 & 14.47 & 10.50 \\
Ab & - & - & - & 1.00 & 26.86 \\
VR-299 & - & - & - & - & 1.00 \\
\hline
\end{tabular}

Data are given as $1 / r$ value; $r=\sqrt{r_{1} \times r_{2}}$ and $r_{1}$ and $r_{2}$ are the titer ratios, calculated as the ratio (heterologous $\div$ homologous titer) for the respective antisera.

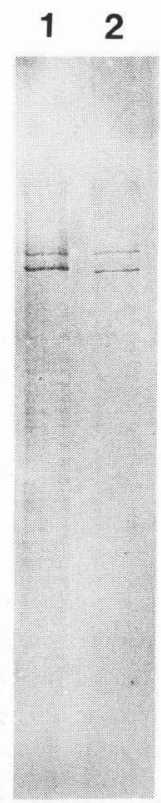

Fig. 1. A comparison of the dsRNA genome segments of YAV and VDV on a 9\% acrylamide slab gel. Lanes: 1, YAV; 2, VDV.

\section{SDS-PAGE analysis of viral polypeptides}

The virus specific polypeptides of VDV, YAV analyzed by immunoprecipitation and SDS-PAGE were shown in Fig. 2. The antisera against YAV immuoprecipitated the polypeptides from VDV infected cells. The virus specific polypeptides of VDV were distinct from YAV. The differences were found in the 43 to $60 \mathrm{kDa}$ molecular weight range.

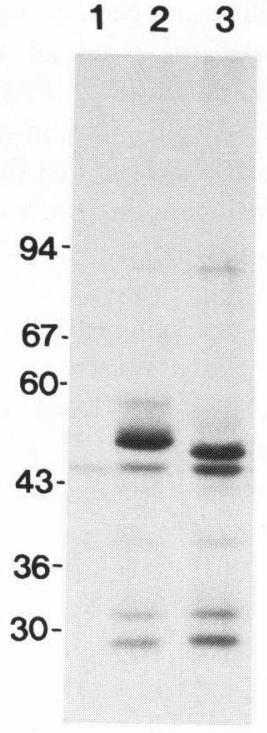

Fig. 2. Comparison of the virus-specific polypeptides of VDV and YAV on 10\% acrylamide gel. The $\left[{ }^{35} \mathrm{~S}\right]$ methionine labelled polypeptides were recovered by immunoprecipitation from infected cell lysates with antisera to YAV. Lanes: 1, mock-infected; 2, YAV-infected; 3, VDV-infected. The numbers on the left side of the figure indicate the molecular weight of marker proteins in $\mathrm{kDa}$.

\section{Discussion}

In the previous study we found that VDV and YAV were closely related by preliminary serological analysis (Nakajima et al., 1993). The detailed serological comparison of the present study confirms the result. The serological comparison of VDV with YAV using $1 / r$ values showed that VDV was almost completely homologous to YAV. On the other hand, the analysis showed that these viruses were distantly related to VR-299, Sp and Ab of IPNV, indicating that these viruses isolated from yellowtail belong to a different serotype of IPNV supporting the results reported by Kusuda et al. (1993).

The genome segment analysis showed that VDV and YAV contained 2 segments of RNA and that these genome of the 2 viruses are distinguishable although the difference between 2 viruses is a little. We previously isolated 12 YAV strains from yellowtail, goldstriped amberjack Seriola aureovittata and threeline grunt Parapristipoma trilineatum and com- 
pared the mobilities of genome segments of them. The genome segments from all $12 \mathrm{YAV}$ isolates showed the same mobilities in PAGE (Nakajima et al., unpublished data). Immunoprecipitation and SDS-PAGE analysis showed that the polypeptides of VDV were distinct from those of YAV. Nakajima et al. (1993) reported the pathological signs of VDV were clearly different from YAV. Thus, the present results of RNA and polypeptides analysis together with pathological effects of the 2 viruses to the host animal indicate that VDV and YAV are distinct birnavirus from each other.

By immunoprecipitation and SDS-PAGE analysis using polyclonal antibodies against each of the birnaviruses, the epitopes and possibly epitopes, which may not be involve in neutralization, on the polypeptide can be studied separately, thus revealing the difference which can not be detected by neutralization test. Hedrick et al. (1985) reported that the mobility of the RNA segments for selective strain is less diagnostic than comparisons made by neutralization and polypeptides electrophoresis.

In the present study, the analysis of polypeptide composition showed clear difference between VDV and YAV in spite of the fact that little difference was found between them by neutralization test and only a slight difference was detected in RNA segment analysis. Thus, immunoprecipitation and SDS-PAGE analysis provides an effective tool for both diagnostic purpose as well as analysis of polypeptides of closely related viruses.

\section{Acknowledgement}

This work was supported in part by a grant from the Ministry of Agriculture, Forestry and Fisheries, Japan. We thank Dr. Y. Inui, National Research Institute of Aquaculture, for reading the manuscript and for helpful comments.

\section{References}

Archetti, I. and F. L. Horsfall (1950): Persistent antigenic variation of influenza A viruses after incomplete neutralization in vivo with heterologous immune serum. J. Exp. Med., 92, 441-462.

Chamberlain, J. P. (1979): Flurographic detection of radioactivity in polyacrylamide gels with the watersoluble fluor, sodium salicylate. Anal. Biochem., 98, 132135.

Hedrick, R. P., W. P. Eaton, J. L. Fryer, Y. C. Hah, J. W. Park and S. W. Hong (1985): Biochemical and serological properties of birnaviruses isolated from fish in Korea. Fish Pathol., 20, 463-468.

Kusuda, R., Y. Nishi, N. Hosono and S. Suzuki (1993): Serological comparison of birnaviruses isolated from several species of marine fish in south west Japan. Fish Pathol., 28, 91-92.

Laemmli, U. K. (1970): Cleavage of the structural proteins during the assembly of the head of bacteriophage $T$ 4. Nature, London, 227, 680-685.

Merril, C. R., D. Goldman, S. A. Sedman and M. H. Ebert (1981): Ultrasensitive strain for proteins in polyacrylamide gels shows regional variation in cerebrospinal fluid proteins. Science, 211, 143-144.

Nakajima, K., K. Ikuta, M. Naito, S. Ueda, S. Kato and K. Hirai (1986): Identification with monoclonal antibodies of virus-specific DNA-binding proteins in the nuclei of cells infected with three serotypes of Marek's disease virus related viruses. J. Virol., 59, 154-158.

Nakajima, K., Y. Maeno, M. Arimoto, K. Inouye and M. Sorimachi (1993): Viral deformity of yellowtail fingerlings. Fish Pathol., 28, 125-129 (in Japanese with English summary).

Okamoto, N., T. Sano, R. P. Hedrick and J. L. Fryer (1983): Antigenic relationships of selected strains of infectious pancreatic necrosis virus (IPNV) and eel virus European (EVE). J. Fish Dis., 6, 19-26.

Reed, L. J. and H. Müench (1938): A simple method of estimating fifty percent endpoints. Am. J. Hyg., 27, 493497.

Sorimachi, M. and T. Hara (1985): Characteristics and pathogenicity of a virus isolated from yellowtail fingerlings showing ascites. Fish Pathol., 19, 231-238 (in Japanese with English summary).

Wattanavijarn, W., C. Torchy, J. Tangtronpipros and P. de Kinkelin (1988): Isolation of a birnavirus belonging to Sp serotype, from southeast Asia fishes. Bull. Eur. Ass. Fish Pathol., 8, 106-108. 